\title{
Design of a Microstrip Dual-Band Bandpass Filter with Compact Size and Tunable Resonance Frequencies for WLAN Applications
}

\author{
M. R. Salehi, E. Abiri, and L. Noori
}

\begin{abstract}
Based on a new open-stub loaded open-loop resonator and step impedance cells, a low insertion losses dual band microstrip filter is designed to create two passbands at almost $2.4 \mathrm{GHz}$ (exactly at $2.35 \mathrm{GHz}$ ) and almost $5.7 \mathrm{GHz}$ (exactly at 5.68GHz) for Multimode Wireless LANs application. The insertion losses at the $2.4 \mathrm{GHz}$ and $5.7 \mathrm{GHz}$ are $0.35 \mathrm{~dB}$ and $0.25 \mathrm{~dB}$ respectively. Also two width fractional bandwidths in its first and second bands are obtained. Several step impedance cells are used in loops and tapped line feed structures to obtain a novel dual band bandpass filter with compact size. The input impedance of the proposed resonator is calculated. The effect of the microstrip stubs and their impedances and impedances on the resonance frequencies is obtained using the input impedance of the proposed resonator.
\end{abstract}

Index Terms-Dual band bandpass filter, step impedance cells, compact size, low insertion loss.

\section{INTRODUCTION}

High performance dual band bandpass filters that operate at IEEE802.11a and IEEE 802.11g Wireless LAN bands play an important role in modern wireless communication systems such as RF transmitters and receivers. For example by using of the microstrip open loop resonators two different dual band bandpass filters operated at $2.4 \mathrm{GHz}$ and $5.7 \mathrm{GHz}$ are designed in [1], [2]. In [3] a compact dual band bandpass filter with small fractional bandwidth using open loop resonators is proposed. In this filter an undesired return loss is seen, where the stopband between two passband is not enough wide. In [4] a dual band band pass filter with very large size and large insertion losses is offered to operate at $1 \mathrm{GHz}$ and $2 \mathrm{GHz}$. In [5] the step impedance coupled lines, short circuited and open circuited stubs are used to design a dual band bandpass filter with asymmetric structure which has high insertion losses. In [6] using the step impedance resonators with very large sizes a high losses dual band bandpass filter is designed for ultra wideband applications. In [7] using the open loop resonators and half wave step impedance resonators a large insertion losses dual band bandpass filter is proposed. In [8] a large size step impedance resonator is used to design a dual band bandpass filter with four transmission zeroes. But it has large insertion loss while its large size problem is not solved. In [9] the asymmetric SIRs and open stubs are used to control the transmission zeros of a proposed dual band bandpass filter.

Manuscript received October 22, 2013; revised March 5, 2014.

The authors are with the Department of Electrical and Electronics Engineering, Shiraz University of Technology, Shiraz, Iran (e-mail: salehi@sutech.ac.ir, abiri@sutech.ac.ir,Leila_noori62@yahoo.com).
Another problem of this filter is its small rejection-band between the two passbands. In [10] a compact dual band bandpass filter is designed by combining bandpass and band-stop filters to operate at $2 \mathrm{GHz}$ and $2.2 \mathrm{GHz}$. In this structure low insertion losses are obtained in the both passbands. But the passbands have the small fractional bandwidths. In [11] a double-slot-loaded resonator is used for exploration of a dual band bandpass filter with two closely spaced passbands operated at $2.1 \mathrm{GHz}$ and $2.6 \mathrm{GHz}$. In this structure a large insertion loss at second passband is obtained. In [12] a small fractional bandwidth dual band bandpass filter is designed and fabricated using open loop resonators for multimode WLANs. This filter has two undesired return loss in the both passbands.

In this paper a compact microstrip filter is designed using two open loop resonators that connected together with mixed coupling. The loops are loaded by simple open stubs. Also in the proposed structure two new tapped lines feed structures are added at the input and output ports to improve impedance matching and achieve dual band bandpass response with good performance in terms of the low insertion losses and the wide fractional bandwidth. This paper is organized as follows: Section II describes design and structure, Section III introduces the simulation results, and Section IV presents the conclusion

\section{DESIGN AND STRUCTURE}

The open loop resonator loaded by three open end stubs is shown in Fig. 1. A novel step impedance taped line feed structure is connected to the open loop resonator to control the resonance frequencies. This taped line feed structure is added to achieve a good impedance matching too. The proposed resonator is divided to nine paths with different impedances and admittances.

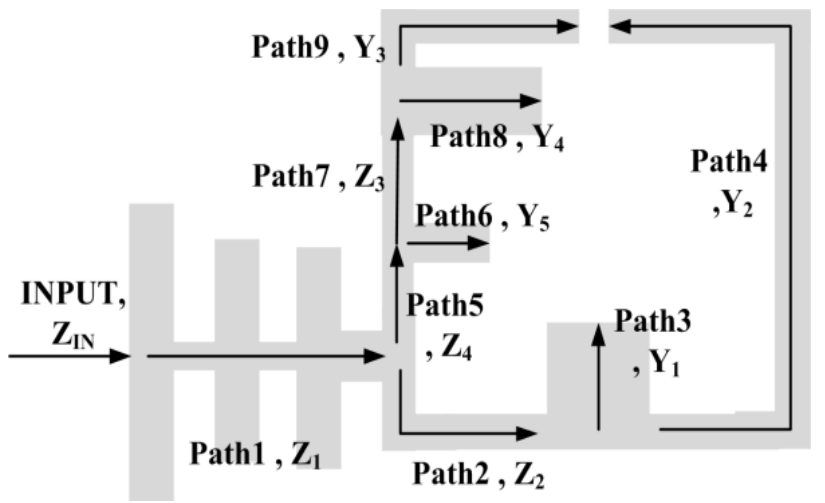

Fig. 1. Proposed microstrip resonator. 
The resonance frequencies of the proposed resonator as shown in Fig. 1 can be controlled by adjusting its input impedance. The equivalent model of the designed resonator is shown in Fig. 2.

From Fig. 2, the input impedance of the proposed resonator as shown in Fig. 1 can be derived as follows:

$$
Z_{\text {in }}=Z_{1}+Z_{2}+Z_{4}+\frac{1}{Y_{1}+Y_{2}}+\frac{1}{\frac{1}{\frac{1}{Y_{3}+Y_{4}}+Z_{3}}+Y_{5}}
$$

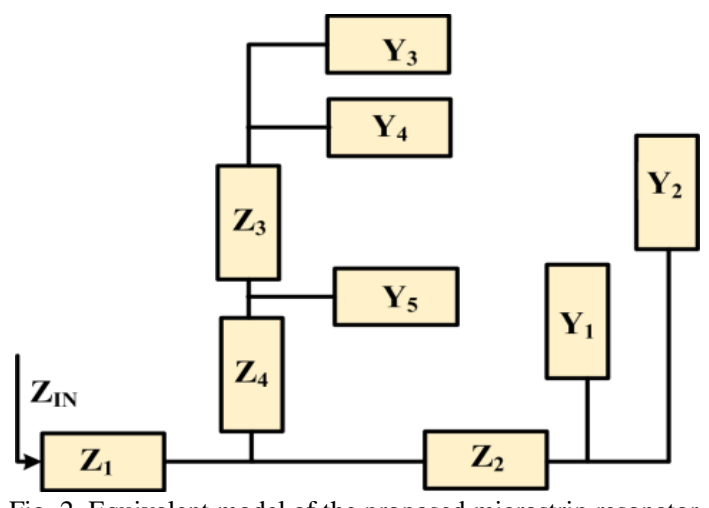

Fig. 2. Equivalent model of the proposed microstrip resonator.

For the even mode when the input admittance is zero, the resonance frequencies are obtained. Therefore from (1) the even mode resonance condition for the proposed microstrip resonator is:

$$
\left(Y_{1}+Y_{2}\right)\left[Y_{5}+\left(Y_{3}+Y_{4}\right)\left(1+Z_{3} Y_{5}\right)\right]=0
$$

From (2), there are different methods to control the resonance frequencies. The first method is obtained from $Y_{1}=$ $-Y_{2}$. In this case $Y_{1}$ can be the admittance of a capacitance $\left(C_{1}\right)$ and $Y_{2}$ can be the admittance of an inductance $\left(L_{1}\right)$. So it can be written that:

$$
Y_{1}+Y_{2}=j \omega_{1} C_{1}+\frac{1}{j \omega_{1} L_{1}}=0
$$

where $\omega_{1}$ is a resonance frequency. Therefore the resonance frequency is as follows:

$$
\omega_{1}=\frac{1}{\sqrt{L_{1} C_{1}}}
$$

Another method to create an even mode resonance frequency can be obtained when the shunt stubs (in the path6, path8, and path9) are supposed as the capacitances and the path7 is assumed as the inductance. Therefore $Y_{3}, Y_{4}$ and $Y_{5}$ are supposed as the admittances of three capacitances $\left(C_{3}, C_{4}\right.$, $C_{5}$ ) and $Z_{3}$ is the impedances of an inductance $\left(L_{3}\right)$. So from (1) the resonance frequency can be achieved as follows:

$$
j \omega_{2}\left(C_{5}+\left(C_{3}+C_{4}\right)\left(1-\omega_{2}^{2} L_{3} C_{5}\right)\right)=0
$$

Therefore

$$
\omega_{2}=\frac{1}{\sqrt{L_{3}}} \times \sqrt{\frac{C_{3}+C_{4}+C_{5}}{C_{5}\left(C_{3}+C_{4}\right)}}
$$

where $\omega_{2}$ is another resonance frequency. So the even mode resonance frequencies can be shifted to the left or right by changing the impedance $Z_{3}$ and admittances $Y_{1}, Y_{2}, Y_{3}, Y_{4}$, and $Y_{5}$. The odd mode resonance condition is obtained when the input admittances is zero. Therefore the odd mode resonance frequency is depends on the tapped line feed structure impedance $\left(Z_{1}\right)$. Each of these resonance frequencies can be selected as the first and second band resonance frequencies. If $\omega_{1}$ and $\omega_{2}$ selected as the first and second resonance frequency, the frequency ratio can be depicted as a function of $L_{1} / L_{3}$ while the capacitances $C_{1}, C_{3}, C_{4}$, and $C_{5}$ are constant. So the frequency ratio $\left(\omega_{2} / \omega_{1}\right)$ as a function of the inductance ratio $\left(L_{1} / L_{3}\right)$ is depicted and shown in Fig. 3.

To obtain the dual band bandpass filter as shown in Fig. 4, two open loop resonators consisting of step the open stubs, the new tapped line feed structures, and the step impedance cells are connected together using mixed coupling. The frequency response of the proposed filter is shown as Fig. 5.

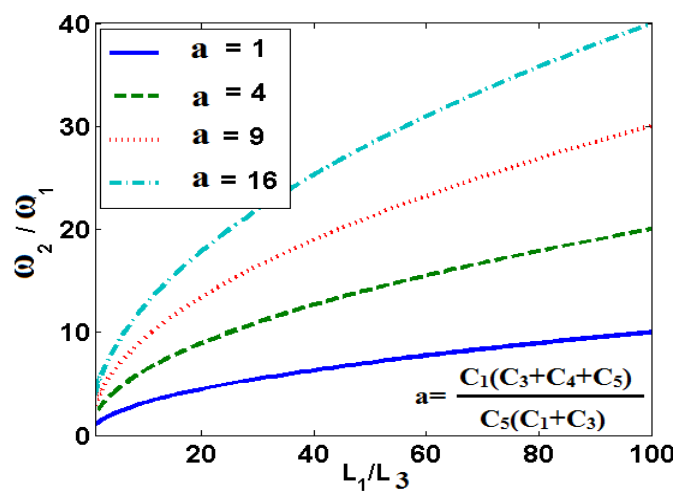

Fig. 3. Resonance frequency ratio as a function of the inductances ratio.

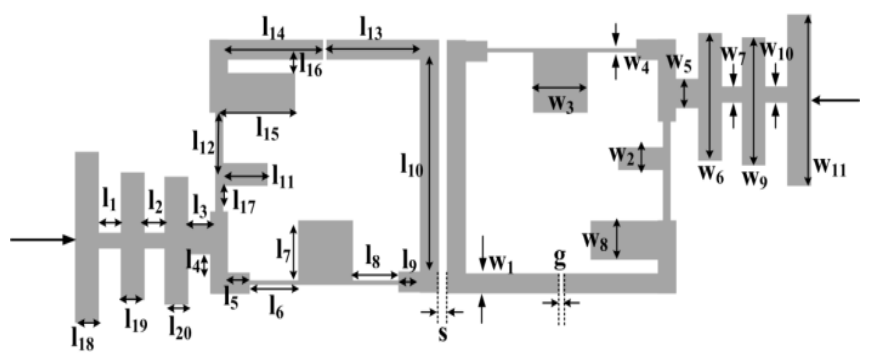

Fig. 4. Proposed dual band bandpass filter.

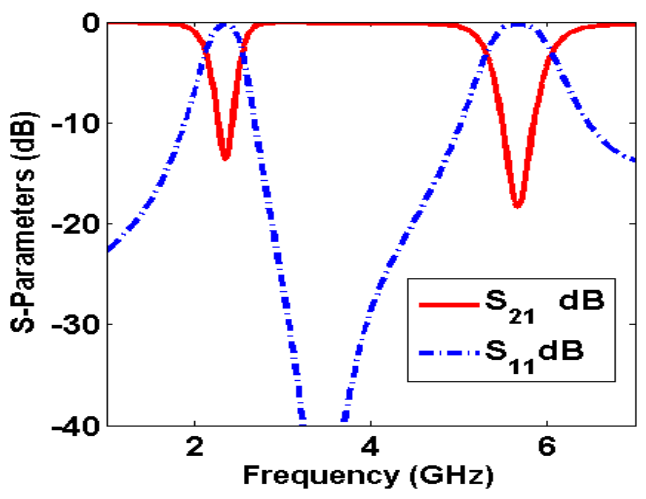

Fig. 5. Frequency response of the proposed dual band bandpass filter. 


\section{SimULATION RESULTS}

This filter is simulated using ADS full wave EM simulator. The proposed filter is designed and fabricated on a RT Duroid 5880 substrate. It has dielectric constant of 2.22, 15 mil-thickness and loss tangent equal to 0.0009 . The dimensions of the proposed structure shown in Fig. 3 are presented in Table I.

TABLE I: DIMENSIONS OF THE PROPOSED FILTER

\begin{tabular}{|c|c|c|c|c|c|c|c|c|}
\hline $1_{1}$ & $1_{2}$ & $1_{3}$ & $1_{4}$ & $1_{5}$ & $l_{6}$ & $l_{7}$ & $l_{8}$ & $l_{9}$ \\
\hline 1 & 1 & 1 & 0.7 & 1 & 2.1 & 2.2 & 2.1 & 1 \\
\hline $1_{10}$ & $1_{11}$ & $1_{12}$ & $1_{13}$ & $1_{14}$ & $1_{15}$ & $1_{16}$ & $1_{17}$ & $1_{18}$ \\
\hline 8.3 & 2 & 2 & 4.2 & 4.2 & 3 & 0.5 & 1 & 1 \\
\hline $1_{19}$ & $1_{20}$ & $\mathrm{w}_{1}$ & $\mathrm{w}_{2}$ & $\mathrm{w}_{3}$ & $\mathrm{w}_{4}$ & $\mathrm{w}_{5}$ & $\mathrm{w}_{6}$ & $\mathrm{w}_{7}$ \\
\hline 1 & 1 & 0.8 & 0.9 & 2.4 & 0.2 & 1.2 & 5 & 0.5 \\
\hline $\mathrm{W}_{8}$ & $\mathrm{w}_{9}$ & $\mathrm{w}_{10}$ & $\mathrm{w}_{11}$ & $\mathrm{~S}$ & $\mathrm{~g}$ & & & \\
\hline 1.5 & 5 & 0.5 & 7 & 0.1 & 0.2 & & & \\
\hline
\end{tabular}

The insertion losses at 2.4 and $5.7 \mathrm{GHz}$ are better than 0.35 and $0.25 \mathrm{~dB}$ respectively, while the return losses in the first and second passbands are better than 13.6 and $18.22 \mathrm{~dB}$ respectively. The filter size is $28.5 \times 12.75 \mathrm{~mm}^{2}$. Fractional Band Widths (FBWs) in the first and second bands are $17 \%$ and $13 \%$ respectively. This filter has $-3 \mathrm{~dB}$ cut-off frequencies at 2.14 and $2.55 \mathrm{GHz}$ in the first passband and 5.31, and 6.04
$\mathrm{GHz}$ in the second passband. The comparison of proposed filter with previous works is shown in Table II. It is seen that the designed filter has smaller size, better insertion losses and good fractional band widths. In the Table II, IL1, IL2, RL1, RL2, FBW1, FBW2, $F_{\mathrm{O} 1}$, and $\mathrm{F}_{\mathrm{O} 2}$ are the insertion loss at $2.4 \mathrm{GHz}$, the insertion loss at $5.7 \mathrm{GHz}$, the first band return loss, the second band return loss, the fractional bandwidth at the first pass band, the fractional bandwidth at the second pass band, the first resonance frequency, and the second resonance frequency respectively.

\section{CONCLUSION}

In this paper a dual band bandpass filter using novel open loop resonators which connecting together with mixed coupling and the new tapped line feed structure was presented to operate at the near the WLAN frequencies. The conditions of obtaining the resonance frequencies were achieved to control the resonance frequencies. The wide fractional bandwidth, and the low insertion losses are achieved. The insertion losses at the $2.4 \mathrm{GHz}$ and $5.7 \mathrm{GHz}$ are $0.35 \mathrm{~dB}$ and $0.25 \mathrm{~dB}$ respectively. The proposed structure was compact and its size was $363 \mathrm{~mm}^{2}$. Also it had two width fractional bandwide in its first and second bands.

\begin{tabular}{|c|c|c|c|c|c|c|c|c|c|}
\hline \multicolumn{1}{|c|}{ TABLE II: COMPARISON OF DESIGNED FILTER WITH PREVIOUS WORKS } \\
\hline $\begin{array}{c}\text { Reference } \\
(\mathrm{dB})\end{array}$ & $\begin{array}{c}\mathrm{IL} 2 \\
(\mathrm{~dB})\end{array}$ & $\begin{array}{c}\mathrm{RL} 1 \\
(\mathrm{~dB})\end{array}$ & $\begin{array}{c}\text { RL2 } \\
(\mathrm{dB})\end{array}$ & $\begin{array}{c}\text { FBW1 } \\
(\Delta 1 \%)\end{array}$ & $\begin{array}{c}\text { FBW2 } \\
(\Delta 2 \%)\end{array}$ & $\begin{array}{c}\mathrm{F}_{\text {o1 }} \\
(\mathrm{GHz})\end{array}$ & $\begin{array}{c}\mathrm{F}_{\text {02 }} \\
(\mathrm{GHz})\end{array}$ & $\begin{array}{c}\text { Size } \\
\left(\mathrm{mm}^{2}\right)\end{array}$ \\
\hline Proposed filter & 0.35 & 0.25 & 13.6 & 18.2 & 17 & 13 & 2.35 & 5.68 & 363 \\
\hline$[1]$ & 0.2 & 0.9 & ----- & ---- & 10 & 8 & 2.71 & 5.05 & 495 \\
\hline$[2]$ & 1.87 & 1.67 & ----- & ---- & ----- & ----- & 2.44 & 5.75 & 655 \\
\hline$[3]$ & 0.9 & 0.2 & ---- & ---- & 3 & 4.5 & 2.65 & 4.67 & 255 \\
\hline$[4]$ & 2.65 & 2.44 & 12.6 & 12.6 & 4.6 & 4.8 & 1 & 2 & 1325 \\
\hline$[5]$ & 6 & 5.3 & ----- & ---- & 4.1 & 5.3 & 2.42 & 5.24 & 434 \\
\hline$[6]$ & 2.12 & 2.33 & 12 & 12 & 10 & 7 & 2.45 & 5.8 & 1905 \\
\hline$[7]$ & 1.85 & 1.9 & ----- & ---- & 12.5 & 25 & 2.46 & 5.6 & 311 \\
\hline$[8]$ & 1.8 & 3 & ----- & ---- & 12 & 7 & 2.45 & 5.8 & 2600 \\
\hline$[9]$ & 1.1 & 1 & 15 & 15 & 6 & 4.8 & 0.8 & 2.45 & 1267 \\
\hline$[10]$ & 0.15 & 0.15 & 15 & 15 & 6.5 & 6 & 2 & 2.24 & 313 \\
\hline$[11]$ & 0.8 & 1.2 & 20 & 20 & 17 & 8.4 & 2.1 & 2.6 & 396 \\
\hline$[12]$ & 0.53 & 0.59 & ------ & ----- & ---- & ----- & 2.4 & 5.2 & 320 \\
\hline
\end{tabular}

\section{REFERENCES}

[1] M. Hayati and L. Noori, "Compact dual band bandpass filter with ultra wide stopband using open loop resonator loaded by T-shape and open stubs," IEICE Electronics Express, vol. 8, no. 14, pp. 1168-1173, 2011.

[2] P. Mondal and M. K. Mandal, "Design of dual band bandpass filters using stub-loaded open-loop resonators," IEEE Trans. on Microwave Theory and Techniques, vol. 56, no. 1, pp. 150 - 155, 2008.

[3] M. Hayati and L. Noori., "Compact dual band bandpass filter using open loop resonator loaded by in-line beeline for wideband applications," IEICE Electronics Express, vol. 8, no. 21, pp. 1789-1794, 2011.

[4] C. H. Tseng and H. Y. Shao, "A new dual band microstrip bandpass filter using net-type resonators," IEEE Microwave and Wireless Components Letters, vol. 20, no. 4, pp. 196-198, 2010.
[5] H. M. Lee and C. C. Tsai, "Dual band filter design with flexible passband frequency and bandwidth selections," IEEE Trans. on Microw. Theory Tech., vol. 55, no. 5, pp. 1002-1009, May 2007.

[6] M. Jiang, L. M. Chang, and A. Chin, "Design of dual-passband microstrip bandpass filters with multi-spurious suppression," IEEE Microw. Wireless Compon. Lett., vol. 20, no. 4, pp. 199-201, 2010.

[7] X. Chen, G. Han, R. Ma, J. Gao, and W. Zhang, "Design of balanced dual band bandpass filter with self-feedback structure," ETRI Journal, vol. 31, no. 4, pp. 475-477, 2009.

[8] J. T. Kuo, T. H. Yeh, and C. C. Yeh, "Design of microstrip bandpass filters with a dual-passband response," IEEE Trans. Microw. Theory Tech., vol. 53, no. 4, pp. 1331-1337, Apr. 2005.

[9] X. Y. Zhang, J. X. Chen, J. Shi, and Q. Xue, "High-selectivity dual band bandpass filter using asymmetric stepped-impedance resonators," Electronics Letters, vol. 45, no. 1, pp. 63-64, 2009.

[10] Y. Heng, X. Guo, B. Cao, B. Wei, X. Zhang, G. Zhang, and X. Song, "Compact superconducting dual band bandpass filter by combining 
bandpass and bandstop filters", Electronics Letters, vol. 49, no. 19, pp. 1230-1232, 2013.

[11] D. Chen, L. Zhu, and C. Cheng, "A novel dual band bandpass flter with closely spaced passbands," IEEE Microw. Wireless Compon. Lett., vol. 24, pp. 38-40, 2014.

[12] M. Hayati, L. Noori, and A. Adinehvand, "Compact dual-band bandpass filter using open loop resonator for multimode WLANs," Electronics Letters, vol. 48, no. 10, pp. 573-574, 2012

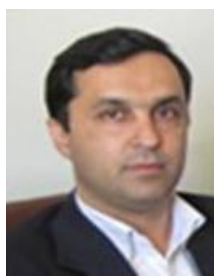

Mohammad Reza Salehi received the B.Sc. degree in electrical engineering from Amirkabir University of Technology (Tehran Polytechnique), Tehran, the M.Sc. degree in electrical engineering from Shiraz University, Shiraz, Iran, and the Ph.D. degree in optoelectronics at the ENSERG/INPG, France. He has authored and co-authored over 85 journal and conference papers and 7 books. He is currently a member of IEEE. His research interests include optoelectronics, optomicrowaves and optical systems.

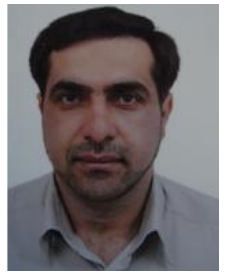

Ebrahim Abiri received the B.Sc. degree in electronics engineering from Iran University of science and technology (IUST) in 1992, M.Sc. degree from Shiraz University in 1996 and the Ph.D. degree in electronic from Iran University of Science and Technology (IUST) in 2007. He has authored more than 50 published technical papers in electronics and power electronics and 4 books. He has been with the Department of Electrical Engineering, Shiraz University of technology (SUTECH), since 2007. His current research activities include analog circuit design and power electronic.

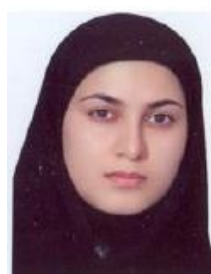

Leila Noori received her B.Sc. and M.Sc. degrees in electronic engineering from Razi University, Kermanshah, Iran in 2005 and 2009 respectively. She currently continues her $\mathrm{Ph} . \mathrm{D}$ in electronic engineering at the Shiraz University of Technology. Her research interests focus on artificial neural networks, microstrip coupler, microstrip filter, and LNAs. 